\title{
Elevated sensitivity to diet-induced obesity and insulin resistance in mice lacking 4E-BP1 and 4E-BP2
}

\author{
Olivier Le Bacquer, ${ }^{1}$ Emmanuel Petroulakis, ${ }^{1}$ Sabina Paglialunga, ${ }^{1,2}$ Francis Poulin, ${ }^{1}$ \\ Denis Richard, ${ }^{2}$ Katherine Cianflone, ${ }^{1,2}$ and Nahum Sonenberg ${ }^{1}$
}

1Department of Biochemistry, McGill University, Montréal, Québec, Canada. ${ }^{2}$ Centre de Recherche Hôpital Laval, Université Laval, Québec City, Québec, Canada.

\begin{abstract}
The most common pathology associated with obesity is insulin resistance, which results in the onset of type 2 diabetes mellitus. Several studies have implicated the mammalian target of rapamycin (mTOR) signaling pathway in obesity. Eukaryotic translation initiation factor 4E-binding (eIF4E-binding) proteins (4E-BPs), which repress translation by binding to eIF4E, are downstream effectors of $m$ TOR. We report that the combined disruption of 4E-BP1 and 4E-BP2 in mice increased their sensitivity to diet-induced obesity. Increased adiposity was explained at least in part by accelerated adipogenesis driven by increased expression of CCAAT/enhancerbinding protein $\delta(\mathrm{C} / \mathrm{EBP} \delta), \mathrm{C} / \mathrm{EBP} \alpha$, and PPAR $\gamma$ coupled with reduced energy expenditure, reduced lipolysis, and greater fatty acid reesterification in the adipose tissue of 4E-BP1 and 4E-BP2 double $\mathrm{KO}$ mice. Increased insulin resistance in 4E-BP1 and 4E-BP2 double $\mathrm{KO}$ mice was associated with increased ribosomal protein S6 kinase (S6K) activity and impairment of Akt signaling in muscle, liver, and adipose tissue. These data clearly demonstrate the role of 4E-BPs as a metabolic brake in the development of obesity and reinforce the idea that deregulated mTOR signaling is associated with the development of the metabolic syndrome.
\end{abstract}

\section{Introduction}

Control of mRNA translation is an important means of regulating gene expression (1). In eukaryotes, translation is tightly controlled at the initiation step, when the $40 \mathrm{~S}$ ribosomal subunit is recruited to the mRNA. The assembly of the eukaryotic translation initiation factor 4F (eIF4F) complex - composed of eIF4E (the mRNA 5' cap-binding protein), eIF4G (a scaffolding protein), and eIF4A (an ATP-dependent RNA helicase) - at the mRNA 5' cap-structure is rate limiting in this process and tightly regulated $(2,3)$. eIF4E activity is regulated through interaction with the inhibitory eIF4E-binding proteins (4E-BPs) (4). In mammals, the $4 \mathrm{E}-\mathrm{BP}$ family consists of 3 proteins, 4E-BP1, 4E-BP2, and 4E-BP3 $(4,5)$. The 4E-BPs compete with eIF4G for a shared binding site on eIF4E, as the binding of 4E-BPs and eIF4G to eIF4E are mutually exclusive (6). Binding of 4E-BP to eIF4E is regulated through phosphorylation: whereas hypophosphorylated forms strongly interact with eIF4E, hyperphosphorylation of 4E-BPs dramatically weakens this interaction (7). In response to growth factors, hormones, or nutrients, the protein kinase mammalian target of rapamycin (mTOR) phosphorylates 2 major downstream targets: 4E-BPs and the ribosomal protein S6 kinases (S6Ks) (8). The activation of mTOR leads to phosphorylation and activation of S6Ks and hyperphosphorylation of 4E-BPs, resulting in dissociation of the 4E-BP from eIF4E (4).

Nonstandard abbreviations used: C/EBP, CCAAT/enchancer-binding protein; DEX, dexamethasone; DKO, double KO; 4E-BP, eIF4E-binding protein; eIF4, eukaryotic translation initiation factor 4; HFD, high-fat diet; HSL, hormone-sensitive lipase; IBMX, 3-isobutyl-1-methylxanthine; IND, indomethacin; IRS-1, insulin receptor substrate 1 ; MEF, mouse embryonic fibroblast; mTOR, mammalian target of rapamycin; NEFA, nonesterified fatty acid; raptor, regulatory associated protein of mTOR; S6K, ribosomal protein S6 kinase; TG, triglyceride; TSC, tuberous sclerosis complex; $\mathrm{VO}_{2}$, oxygen consumption.

Conflict of interest: The authors have declared that no conflict of interest exists. Citation for this article: J. Clin. Invest. 117:387-396 (2007). doi:10.1172/JCI29528.
Recently, 4E-BP1 and S6K1 were shown to control insulin sensitivity and obesity (9-13). The mTOR pathway is also involved in the control of adipogenesis and adipocyte differentiation (14-16). Rapamycin, a specific inhibitor of mTOR, reduces adipocyte clonal expansion and differentiation in human and rodent cells $(15,16)$. The effect of rapamycin on adipogenesis is a consequence of decreased expression of 2 late-phase adipocyte differentiation transcription factors, PPAR $\gamma$ and CCAAT/enhancer-binding protein- $\alpha(\mathrm{C} / \mathrm{EBP} \alpha)(14)$. Furthermore, the activities of mTOR and $\mathrm{S} 6 \mathrm{~K}$ are increased in the liver and skeletal muscle of rats fed a highfat diet (HFD) (12). Increased mTOR activity engenders a negative feedback loop that inactivates insulin receptor substrate 1 (IRS-1). The phosphorylation of IRS- 1 serine residue 636/639 reduces the activity of IRS-1 and impairs the PI3K/Akt signaling pathway (17). This inhibitory effect is reversed in vitro by rapamycin (12). Deletion of S6K1 protects Akt from this negative feedback, further demonstrating that the mTOR/S6K1 pathway exerts a negative effect on PI3K/Akt activity (18).

Tuberous sclerosis complex 1 and 2 (TSC1 and TSC2; also known as hamartin and tuberin, respectively) form a GTPase-activating complex for the small GTPase protein Rheb, which stimulates mTOR activity (19). Therefore TSC $1 / 2$ is an upstream inhibitor of the mTOR pathway (20). In Drosophila, TSC1 deletion leads to increased S6K activation and reduced Akt activity (21). Similarly, loss of TSC $1 / 2$ activates mTOR and disrupts the PI3K/Akt pathway (22). Consistent with this model, deletion of S6K1 protects against age- and diet-induced obesity while enhancing insulin sensitivity (11). In S6K1 KO mice that were fed a HFD, Akt signaling was not reduced as it was in WT mice on the HFD (11). Furthermore, S6K1 KO mice exhibit reduced IRS-1 phosphorylation on Ser307 and Ser636/639, residues known to be associated with insulin resistance $(11,23)$. Similarly, 2 genetic models of obesity, $o b / o b$ and $K / K A^{y}$ mice, exhibit markedly increased S6K1 activity and increased phosphorylation of IRS-1 on Ser307 and Ser636/639 


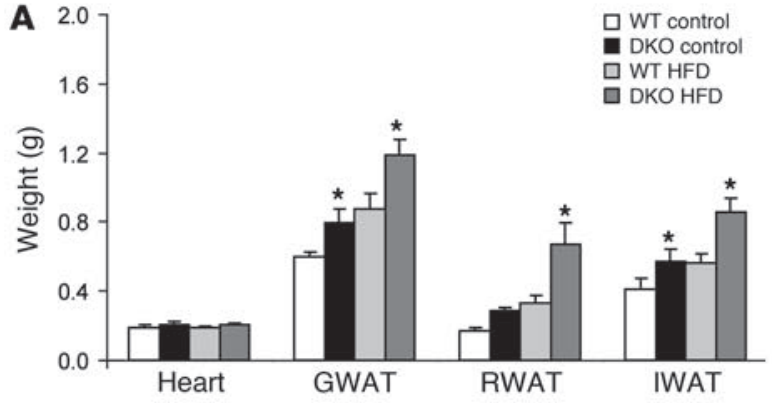

B

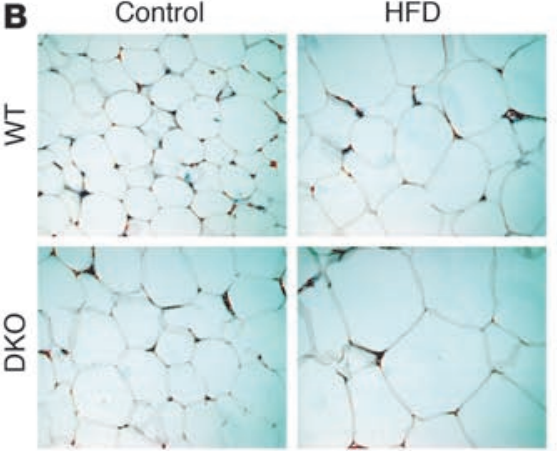

C
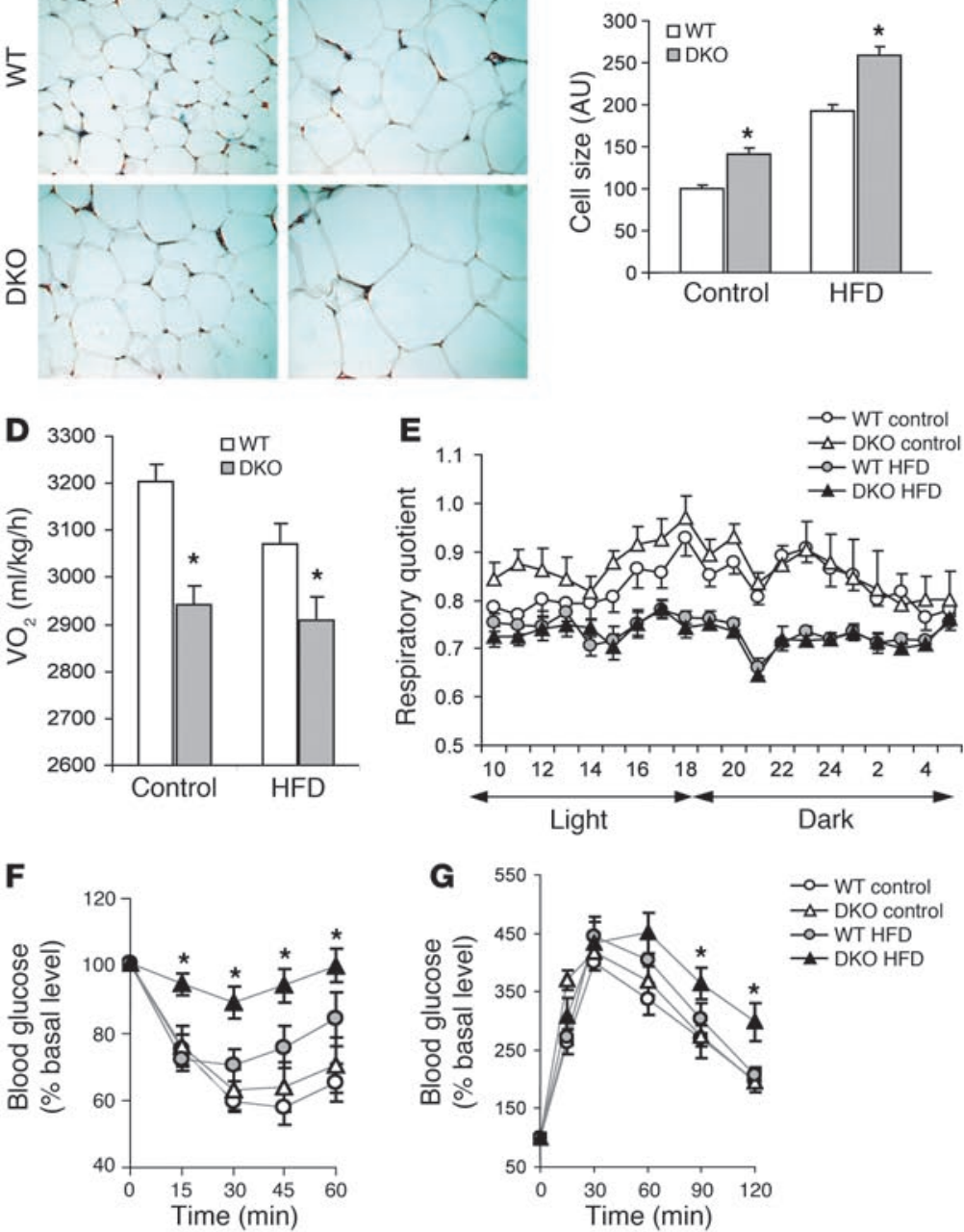

Figure 1

Increased obesity and insulin resistance in 4E-BP1 and 4E-BP2 DKO mice. (A) Weight of the heart, gonadal (GWAT), retroperitoneal (RWAT), and inguinal (IWAT) white adipose tissue $(n=7-10)$ of WT and DKO mice fed HFD or normal chow diet (control). (B) Histological analysis of WT and DKO gonadal white adipose tissue from mice fed normal chow or HFD. Sections obtained from 4 different animals were stained with hematoxylin and eosin. Original magnification, $\times 400$. (C) Adipocyte cell size in WT and DKO gonadal adipose tissue. (D) Mean $\mathrm{VO}_{2}$ in WT and DKO mice fed normal chow or HFD $(n=5)$. (E) Respiratory quotient, calculated as the ratio of $\mathrm{VO}_{2}$ to carbon dioxide production, in WT and DKO mice fed normal chow or HFD during light and dark phases. (F) Insulin resistance test. Fed mice given normal chow or HFD received an intraperitoneal injection of $0.75 \mathrm{U} / \mathrm{kg}$ insulin, and blood samples were taken at the indicated times $(n=7-14)$. (G) Glucose tolerance test. Mice fed normal chow or HFD were fasted overnight before receiving an intraperitoneal injection of $2 \mathrm{~g} / \mathrm{kg}$ glucose, and blood samples were taken at the indicated times $(n=7-14)$. Data are mean \pm SEM. ${ }^{*} P<0.05$ versus WT (2-tailed, unpaired Student's $t$ test).

ing to inactivation of Akt signalling in muscle, liver, and adipose tissue.

\section{Results}

Increased adiposity in $4 E-B P 1$ and $4 E-B P 2$ DKO mice. Both 4E-BP1 and 4E-BP2 are highly expressed in tissues involved in glucose and lipid homeostasis, including adipose tissue, pancreas, liver, and muscle (10). Because both 4E-BP1 and 4E-BP2 are expressed in these tissues, we chose to investigate their roles in metabolism by generating 4E-BP1 and 4E-BP2 DKO mice. The deletion of 4E-BP1 and 4E-BP2 was confirmed by PCR and Western blotting (Supplemental Figure 1; supplemental material available online with this article; doi:10.1172/JCI29528DS1). Eight-week-old DKO and WT mice were fed a control normal chow diet and monitored over a period of 16 weeks. The weight gain was $29 \%$ higher in DKO than in WT mice $(7.2 \pm 0.2 \mathrm{~g}$ and $5.6 \pm 0.2 \mathrm{~g}$, respectively; $P<0.05)$. This difference was not a result of hyperphagia, as food intake was identical for WT and DKO mice $(9.9 \pm 0.6 \mathrm{kcal} / \mathrm{d} / \mathrm{mouse}$ and $10.6 \pm 0.6 \mathrm{kcal} / \mathrm{d} /$ mouse, respectively). The observed increase in body weight in DKO mice can be explained at least in

(11). In a mixed BALB/c 129SvJ1 genetic background, deletion of $4 \mathrm{E}-\mathrm{BP} 1$ results in a reduction in adipose tissue (10). This phenotype is explained in part by the conversion of white adipose tissue into brown adipose tissue as detected by overexpression of 2 specific markers of brown adipose tissue, uncoupling protein 1 (UCP1) and PPAR $\gamma$ coactivator $1 \alpha($ PGC- $1 \alpha)(10)$. To better understand the role of the 4E-BPs in fat metabolism and metabolic diseases, we examined 4E-BP1 and 4E-BP2 double KO (DKO) mice. $\mathrm{DKO}$ mice exhibit increased sensitivity to diet-induced obesity and insulin resistance. Increased adiposity was due to increased adipogenesis coupled with alteration in fat metabolism and energy expenditure. DKO mice also exhibit increased S6K1 activity lead- part by an increase in fat accumulation (Figure 1A). Histological examination of epididymal adipocytes by hematoxylin and eosin staining showed a $40 \%$ increase in cell size in DKO mice $(P<0.01$; Figure 1, B and C). The change in fat accumulation was associated with a rise in serum insulin and cholesterol levels (Table 1). Taken together, these data demonstrate that disruption of 4E-BP1 and 4E-BP2 results in the development of an obese phenotype.

To further characterize the DKO phenotype, 8-week-old mice were subjected to a HFD for 16 weeks. While on the HFD, DKO mice gained $22 \%$ more weight than did WT mice $(10.8 \pm 0.4 \mathrm{~g}$ and $8.8 \pm 0.4 \mathrm{~g}$, respectively; $P<0.01)$. The increased body weight observed in the DKO mice was not due to increased food intake 
Table 1

4E-BP1 and 4E-BP2 DKO mice display altered metabolic parameters

\begin{tabular}{lcccc} 
& \multicolumn{2}{c}{ WT } & \multicolumn{2}{c}{ DKO } \\
& Normal chow & HFD & Normal chow & HFD \\
Weight $(\mathrm{g})$ & $28.5 \pm 0.4$ & $31.2 \pm 0.57$ & $31.3 \pm 0.2^{\mathrm{A}}$ & $34.7 \pm 0.4^{\mathrm{A}}$ \\
Weight gain $(\mathrm{g})$ & $5.6 \pm 0.2$ & $8.8 \pm 0.4$ & $7.2 \pm 0.2^{\mathrm{A}}$ & $10.8 \pm 0.4^{\mathrm{A}}$ \\
Glucose $(\mathrm{mg} / \mathrm{dl})$ & $87 \pm 8$ & $146 \pm 7$ & $72 \pm 5$ & $180 \pm 10^{\mathrm{A}}$ \\
Insulin $(\mathrm{mg} / \mathrm{l})$ & $1.92 \pm 0.29$ & $2.36 \pm 0.49$ & $2.51 \pm 0.30$ & $4.40 \pm 0.71^{\mathrm{A}}$ \\
Cholesterol $(\mathrm{mM})$ & $4.20 \pm 0.17$ & $4.69 \pm 0.19$ & $5.02 \pm 0.22^{\mathrm{A}}$ & $5.54 \pm 0.17^{\mathrm{A}}$ \\
HDL-cholesterol (mM) & $3.23 \pm 0.18$ & $3.71 \pm 0.17$ & $3.87 \pm 0.23^{\mathrm{A}}$ & $4.36 \pm 0.21^{\mathrm{A}}$ \\
NEFA (mM) & $1.84 \pm 0.12$ & $1.47 \pm 0.10$ & $1.92 \pm 0.14$ & $1.61 \pm 0.13$ \\
TGs (mM) & $2.05 \pm 0.16$ & $1.32 \pm 0.08$ & $2.12 \pm 0.12$ & $1.44 \pm 0.10$ \\
Leptin (ng/ml) & $12.6 \pm 1.4$ & $21.3 \pm 3.8$ & $16.1 \pm 2.0$ & $37.4 \pm 4.8^{\mathrm{A}}$ \\
\hline
\end{tabular}

Mice were 24 weeks old $(n=10-15)$. Data are mean \pm SEM. ${ }^{A} P<0.05$ versus WT (2-tailed, unpaired Student's $t$ test).

(WT, $12.7 \pm 0.9 \mathrm{kcal} / \mathrm{d} / \mathrm{mouse} ;$ DKO, $12.6 \pm 0.6 \mathrm{kcal} / \mathrm{d} / \mathrm{mouse}$ ), but can be explained by a large accumulation of white adipose tissue, mainly due to increased adipocyte size (Figure $1, \mathrm{~A}-\mathrm{C}$ ). The increased body weight of the DKO mice was also associated with increased liver weight (Figure 2B). Histological analysis of WT and DKO mouse livers clearly demonstrated the development of steatosis (Figure 2A), with a more pronounced accumulation of triglycerides (TGs) in DKO liver (Figure 2C), reinforcing the finding of increased systemic adiposity in DKO mice.

In DKO mice on the HFD, serum glucose, insulin, cholesterol, and HDL-cholesterol levels were all significantly increased (Table 1). Leptin, the product of the $o b$ gene, is a satiety hormone that is mainly synthesized and secreted by white adipose tissue (24). Its production is regulated by nutritional signals, and it is an indicator of long-term energy surplus. Consistent with the increased adipose tissue mass, circulating leptin levels were increased in HFDfed DKO mice by $75 \%$ compared with HFD-fed WT mice $(P<0.05$; Table 1). The levels of circulating TGs and nonesterified fatty acids (NEFAs) were not significantly different (Table 1 ). The growth curves and HFD-induced fat accumulation and insulin resistance test results for single 4E-BP1 KO and 4E-BP2 KO mice (Supplemental Table 1, Supplemental Figures 2 and 3, and Supplemental Results) suggest a synergetic effect of 4E-BP1 and 4E-BP2 in the obesity phenotype of the DKO mice.

Importantly, the metabolic rate was reduced in the DKO mice, as indicated by a $10 \%$ decrease in oxygen consumption $\left(\mathrm{VO}_{2}\right)$ compared with WT mice (Figure 1D). The normal chow diet-fed DKO mice demonstrated a significantly higher respiratory quotient (calculated as the ratio of $\mathrm{VO}_{2}$ to carbon dioxide production) than did normal chow diet-fed WT mice $(0.868 \pm 0.007$ versus $0.817 \pm 0.008$, respectively; $P<0.0001$, 2-way ANOVA; Figure 1E) during the light phase. This indicates that the DKO mice preferentially maintained carbohydrate utilization as their fuel source, possibly to preserve their fat reserves. In contrast, WT mice shifted toward a greater uti-

\section{Figure 2}

Liver histology in WT and DKO mice. (A) Histological analysis of WT and DKO liver from mice fed normal chow or HFD. Sections obtained from 4 different animals were stained with hematoxylin and eosin. Original magnification, $\times 400$. (B) Liver weight of WT and DKO mice fed HFD or normal chow. (C) Liver total TG content. Data are mean \pm SEM. ${ }^{*} P<0.05$ versus WT (2-tailed, unpaired Student's $t$ test). lization of fat. In both WT and DKO mice fed the HFD, the respiratory quotient was reduced to a similar level, demonstrating a shift to fat utilization (Figure 1E).

Increased insulin resistance in DKO mice. It is thought that obesity and lipid accumulation are responsible for reduced insulin action, leading to the development of insulin resistance and metabolic syndrome $(25,26)$. Therefore, WT and DKO mice were treated with insulin to monitor insulin resistance. The glucose clearance level was similar in DKO and WT mice fed the normal chow diet (Figure 1F). HFD feeding caused the development of insulin resistance in both DKO and WT mice, as demonstrated by the reduced ability of insulin to decrease blood glucose levels (Figure 1F). The higher level of insulin found in DKO mice (Table 1) indicates that the 4E-BPs are required for a normal response to insulin. Indeed, we observed a greater impairment of insulin action in the DKO mice (Figure 1F). Furthermore, both WT and DKO mice fed the HFD displayed impaired glucose tolerance (Figure 1G), with a more pronounced effect in the DKO mice.

Deletion of $4 E-B P 1$ and $4 E-B P 2$ promotes S6K activity. A negative feedback loop by which S6K1 inhibits the PI3K/Akt pathway has been previously described $(11,12,18,27)$. S6K1 activation inhibits insulin signaling by phosphorylating IRS-1, which leads to its degradation and subsequent inhibition of signaling to Akt. Because the DKO mice display an obese phenotype opposite to the lean S6K1 KO phenotype (11), and because 4E-BPs and S6Ks are both targets of mTOR, we suspected that S6K1 could be deregulated in DKO mice. In control mice, Ser473Akt phosphorylation was dramatically increased in adipose tissue, muscle, and livers $10 \mathrm{~min}$ utes after insulin injection (Figure 3A and Supplemental Figure 4).

A
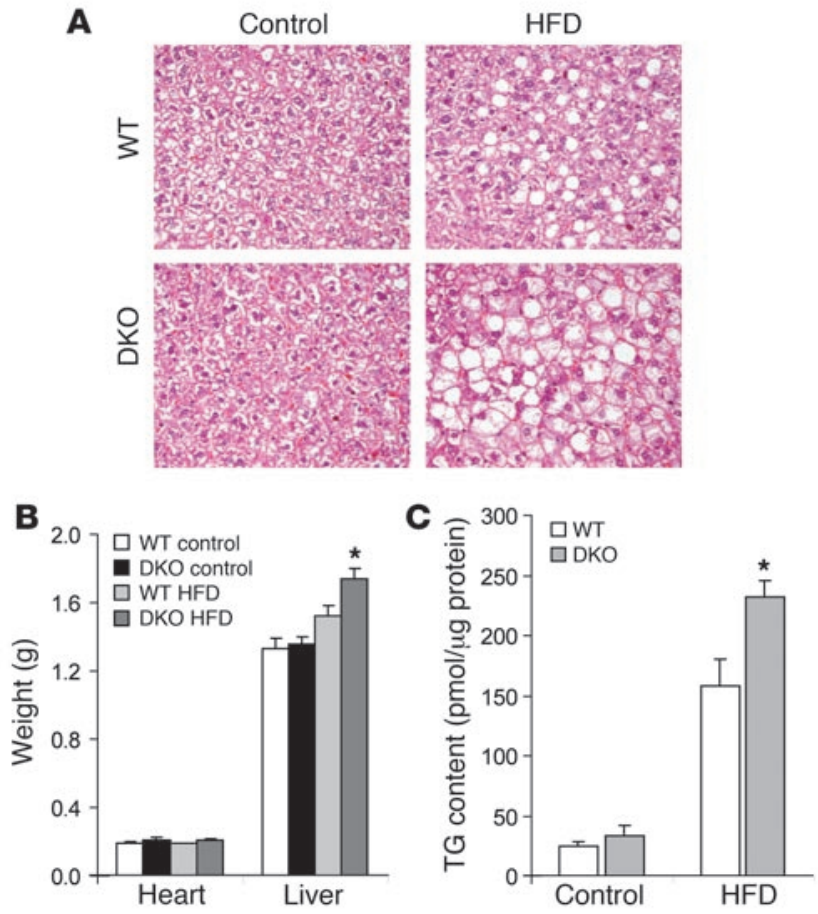
A
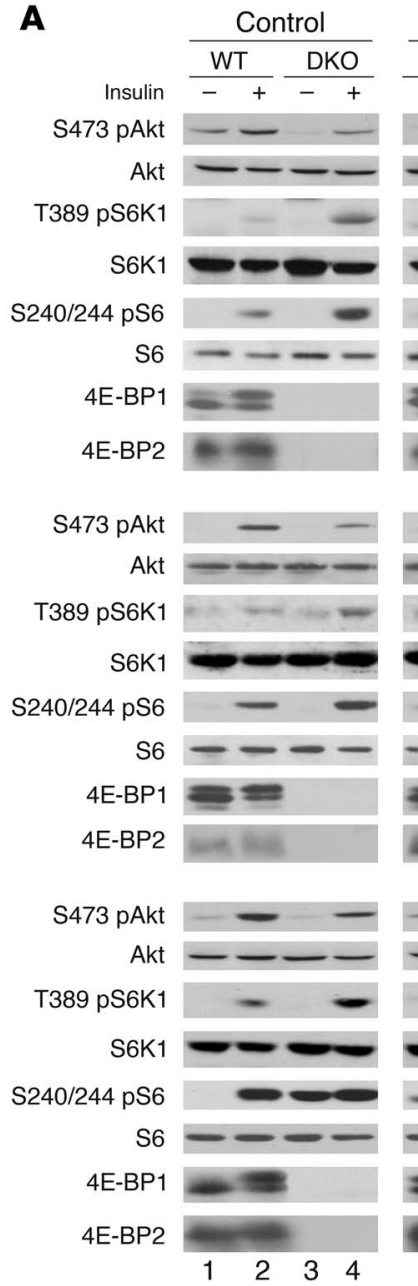
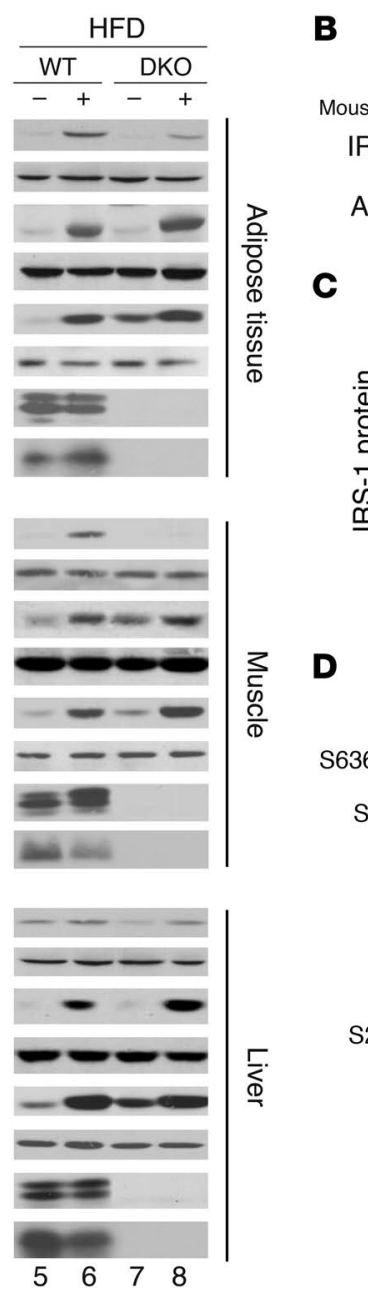

B

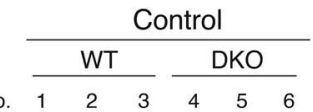

IRS-1

Actin

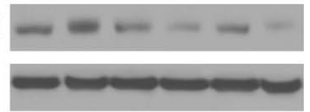

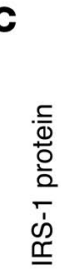

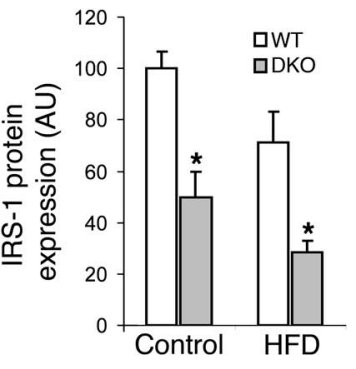

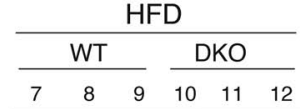
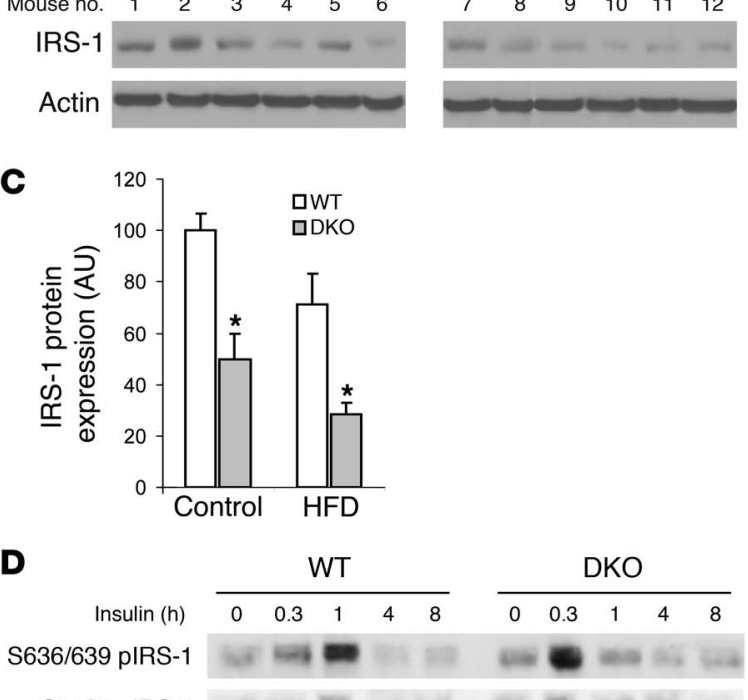

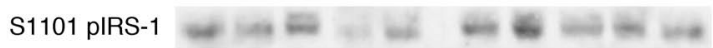

IRS-1 $----\cdots---\cdots$

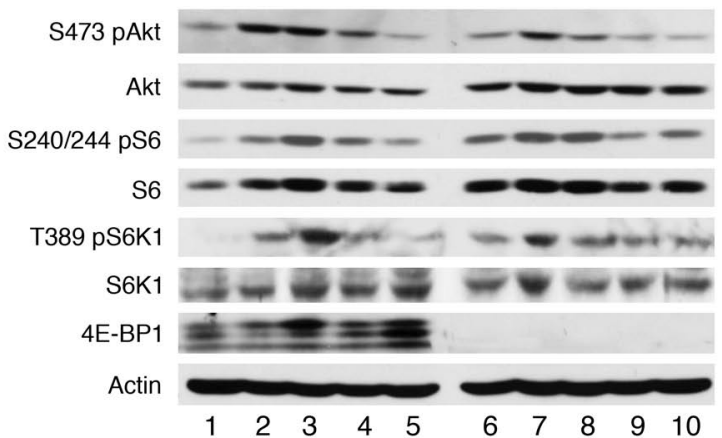

Figure 3

Deletion of 4E-BP1 and 4E-BP2 led to impairment of insulin signaling. (A) Increased S6K activity and reduced Ser473 phosphorylation of Akt in muscle, liver, and adipose tissue from WT and DKO animals. Mice were fasted for 6 hours before receiving a $0.75 \mathrm{U} / \mathrm{kg}$ insulin injection in the tail vein. Animals were sacrificed 10 minutes later, and tissues were collected for Western blotting. An immunoblot of WT and DKO mouse tissue is shown. S473 pAkt, phosphorylated Ser473 of Akt; T389 pS6K1, phosphorylated Thr389 of S6K1; S240/244 pS6, phosphorylated Ser240/244 of S6. (B) Reduced IRS-1 expression in DKO adipose tissue. (C) Quantification of IRS-1 protein levels in WT and DKO adipose tissue. Levels were normalized to actin $(n=6-7)$. Data are mean \pm SEM. ${ }^{*} P<0.05$ versus WT (2-tailed, unpaired Student's $t$ test). (D) Immunoblot analysis showed increased inhibitory serine phosphorylation of IRS-1 (S636/639 pIRS-1 and S1101 pIRS-1) and sustained Thr389 phosphorylation of S6K1 in DKO MEFs following insulin treatment.

However, Akt phosphorylation was increased to a much lesser extent in DKO mouse tissues. The decrease in Akt phosphorylation correlated with an increase in S6K activity, as indicated by increased S6K1 and S6 phosphorylation (Figure 3A and Supplemental Figure 4). HFD and obesity are associated with overactivation of the mTOR pathway, particularly with increased S6K activity in muscle and liver (12). S6K activity is also increased in 2 models of genetic obesity, $o b / o b$ and $K / K A^{y}$ mice (11). HFD feeding caused an increase in S6K1, S6, and 4E-BP1 phosphorylation in WT mice (reflected by an increase in upper slower migrating bands; Figure 3A, compare lanes 1 and 5) indicative of elevated mTOR activity. Akt phosphorylation in HFD-fed DKO mice was drastically impaired, which is consistent with increased obesity, insulin resistance, and glucose intolerance (Figure 3A and Supple- mental Figure 4). Overactivation of the mTOR pathway is also associated with a reduction in IRS-1 protein level $(18,27)$. Because S6K activity was increased in our model and is involved in the control of IRS-1 activity, we examined IRS-1 expression in adipose tissue. IRS-1 protein levels were reduced by approximately $35 \%$ in normal chow diet-fed DKO mice and approximately $60 \%$ in HFD-fed DKO mice as compared with WT mice $(P<0.05$; Figure 3 , B and C). Under such conditions, the insulin receptor- $\beta$ expression in adipose tissue was reduced by approximately $35 \%$ in both WT and DKO mice fed the HFD (Supplemental Figure 5). These data suggest that reduced insulin signaling is a consequence of reduced IRS-1 protein levels.

To examine the effect of 4E-BP1 and 4E-BP2 disruption on insulin signaling in a cell-autonomous system and to study the long- 
A
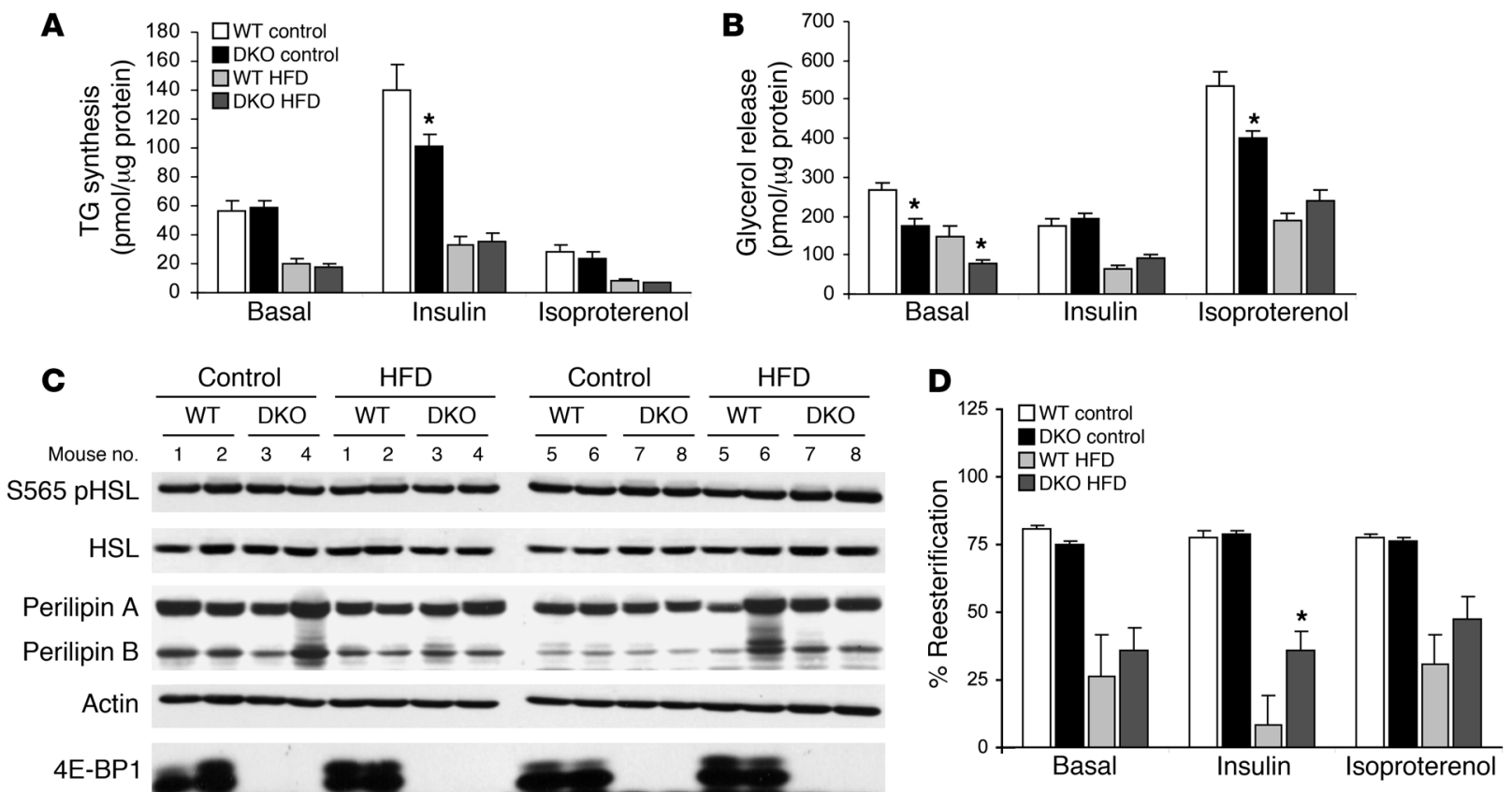

Figure 4

Deletion of 4E-BP1 and 4E-BP2 altered lipid metabolism. Adipose tissue was collected from fasted mice on control or high fat diet and incubated in $5 \mathrm{mM}$ glucose $\mathrm{Ca}^{2+-}$-free Krebs-Ringer buffer containing 1\% fatty acid-free BSA (basal), with $100 \mathrm{nM}$ insulin or $10 \mu \mathrm{M}$ isoproterenol as described in Methods $(n=5)$. (A) TG synthesis was measured in isolated adipose tissue. (B) Lipolysis was reduced in DKO adipose tissue. (C) Western blot analysis of lipolysis-associated proteins. S565 pHSL, phosphorylated Ser565 of HSL. (D) Increased fatty acid reesterification in DKO adipose tissue. Data are mean \pm SEM. ${ }^{*} P<0.05$ versus WT (2-way ANOVA).

term effects of insulin, mouse embryonic fibroblasts (MEFs) were used. In DKO and WT MEFs, insulin treatment led to an increase in S6K1 phosphorylation (Figure 3D). However, S6K1 phosphorylation was already elevated in serum-starved DKO MEFs (Figure $3 \mathrm{D}$, compare lanes 1 and 6 ), and the kinetics of the insulin-stimulated S6K1 phosphorylation were accelerated - with maximum phosphorylation at 20 minutes after insulin administration - and maintained for 8 hours (Figure 3D, compare lanes 2 and 7). In contrast, in WT MEFs, S6K1 phosphorylation was sustained up to 1 hour after insulin treatment and then returned to basal levels by 4 hours after treatment (Figure 3D). Constitutive activation of S6K1 in DKO MEFs was also associated with reduced phosphorylation of Akt, indicating that the DKO MEFs were less sensitive to insulin treatment (Figure 3D, compare lanes 2 and 7). Because S6K1 activation is associated with obesity and increased serine phosphorylation of IRS-1 $(11,12)$, IRS-1 phosphorylation was also examined. In DKO MEFs the accelerated S6K1 phosphorylation correlated with a faster phosphorylation of IRS-1 on Ser636/639 and Ser1101 residues (Figure 3D, compare lanes 2 and 7), explaining the reduced activation of Akt. Both of these sites are associated with inhibition of insulin signaling $(23,28)$, and Ser636/639 phosphorylation has been demonstrated to be associated with type 2 diabetes (23).

Lipid metabolism is altered in DKO adipose tissue. Next, in order to determine whether fat accumulation in DKO mice is a consequence of increased lipogenesis or reduced lipolysis, TG synthesis, glycerol release, and reesterification were examined in isolated gonadal adipose tissue. Basal TG synthesis was similar in DKO and WT mice. Insulin caused a 2.5 -fold increase in TG synthesis in WT mice, whereas the same treatment in DKO mice fed the normal chow diet led to only a 1.7 -fold increase (Figure 4A). This result is consistent with the impaired insulin signaling observed in DKO mice (Figure 3). Treatment with isoproterenol, a specific activator of lipolysis, reduced TG synthesis to the same extent in WT and DKO mice (Figure 4A). Lipolysis was then examined using glycerol release as an index of lipid breakdown. Basal lipolysis was lower in adipose tissue of DKO mice compared with WT mice (approximately $32 \%$ on chow diet and $47 \%$ on HFD as compared to WT levels; $P<0.05$; Figure 4B). The decreased lipolysis could be a major contributor to the development of obesity. Upon treatment with insulin, lipolysis was inhibited in WT mice, but not in DKO mice. This is also consistent with our finding that DKO mice were insulin resistant (Figure 1F). Isoproterenol treatment increased lipolysis to the same extent in both WT and DKO mice (Figure 4B). Further investigation revealed no significant differences in the levels of 2 proteins involved in the control of lipolysis in adipocytes, hormone-sensitive lipase (HSL), Ser565-phosphorylated HSL (29, 30 ), and perilipin $(31,32)$, in DKO adipose tissue (Figure 4C). Thus, alterations in components of the lipolysis pathway are not responsible for decreased basal lipolysis in DKO adipose tissue.

Fatty acid reesterification could also contribute to the difference in fat accumulation between WT and DKO mice. During lipolysis, NEFAs and glycerol are released from adipocyte TGs (at a ratio of 3:1). Although the glycerol cannot be reused by the adipocytes, the NEFAs can be reesterified to produce new TGs. Thus, the ratio of glycerol levels to NEFA levels provides an index of reesterification (33). In mice fed the normal chow diet, approximately $75 \%-80 \%$ of fatty acids were efficiently taken up by adipocytes and stored as TGs, with no difference between WT and DKO mice (Figure 4D). Fatty acid reesterification was decreased by approximately $30 \%-40 \%$ in mice fed the HFD due to an increase in fatty acids made readily avail- 

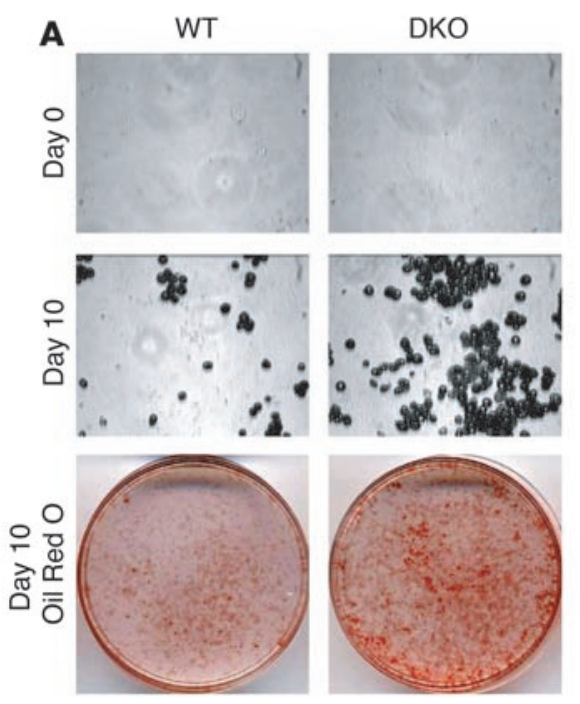

$$
\text { D }
$$

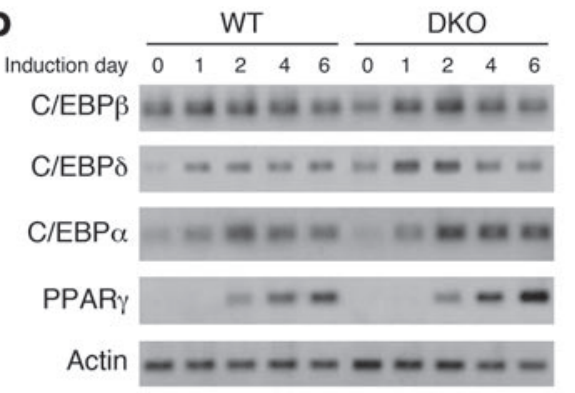

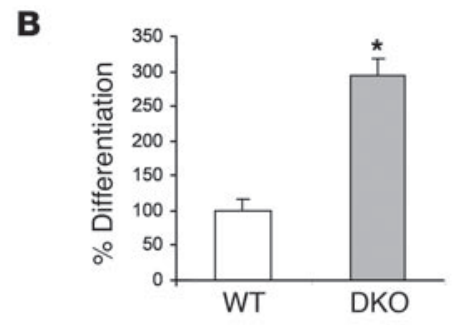
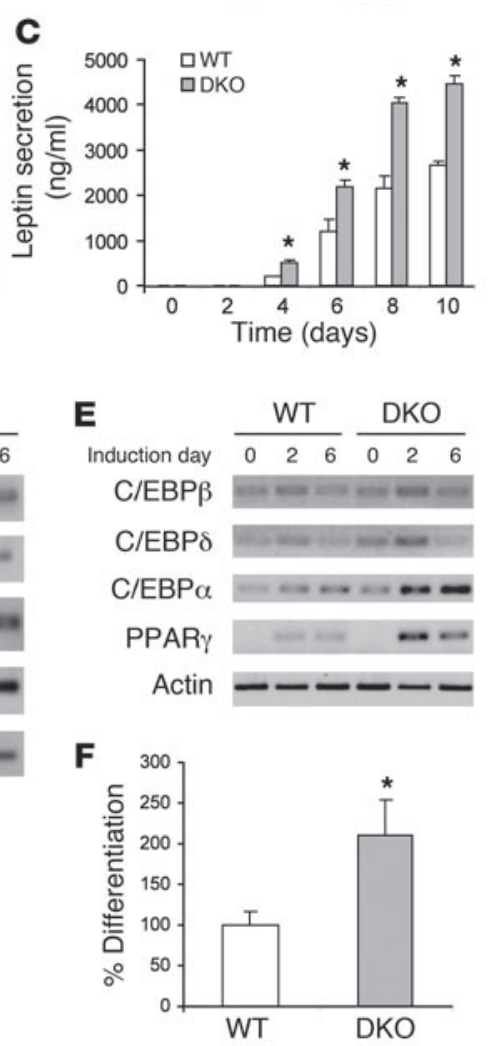

\section{Figure 5}

Deletion of 4E-BP1 and 4E-BP2 promotes adipocyte differentiation. MEFs from WT and DKO embryos were grown to confluence and differentiated into adipocytes as described in Methods. (A) Microscopic images of MEFs following induction of adipogenesis. Original magnification, $\times 400$. Lipid droplets were stained with oil red $O$ solution. (B) Quantification of lipid incorporation by measurement of the intensity of oil red O staining in WT and DKO MEFs at day 10 of the adipocyte differentiation process. (C) Leptin secretion in the culture medium was measured throughout induction of adipogenesis and quantified. (D) RT-PCR analysis showing C/EBP $\beta$, $\mathrm{C} / \mathrm{EBP} \delta, \mathrm{C} / \mathrm{EBP} \alpha$, and PPAR $\gamma$ expression following differentiation of WT and DKO MEFs. (E) RT-PCR analysis showing $\mathrm{C} / \mathrm{EBP} \beta, \mathrm{C} / \mathrm{EBP} \delta, \mathrm{C} / \mathrm{EBP} \alpha$, and PPAR $\gamma$ expression following differentiation of preadipocytes isolated from WT and DKO adipose tissue. (F) Lipid incorporation was quantified by measuring the intensity of oil red O staining in WT and DKO preadipocytes at day 10 of the adipocyte differentiation process. Data are mean \pm SEM from 4 different experiments. ${ }^{*} P<0.05$ versus WT (2-tailed, unpaired Student's $t$ test). able by the diet. Insulin dramatically reduced fatty acid reesterification in WT mice fed the HFD, but reesterification was maintained at $35 \%$ in HFD-fed DKO mice (Figure 4D). Taken together, these data demonstrate that reduced lipolysis and increased insulin-stimulated reesterification cause an increase in fat accumulation in DKO mice.

Increased adiposity is associated with enhanced adipocyte differentiation in DKO cells. Because increased adiposity in the DKO mice could also be due to increased adipocyte differentiation, adipogenesis was investigated using primary MEFs. Adipocyte differentiation was induced in MEFs using 3-isobutyl-1-methylxanthine, dexamethasone, and indomethacin (IBMX/DEX/IND), and lipid droplets were detected with oil red O staining (34). Adipocyte differentiation was increased in DKO MEFs compared with WT MEFs (Figure 5A). Remarkably, the difference in differentiation was not caused by increased DKO MEF proliferation, as this was identical to that of WT MEFs under standard culture conditions (data not shown). The extent of differentiation for WT, DKO, 4E-BP1 $\mathrm{KO}$, and 4E-BP2 $\mathrm{KO}$ cells was determined by quantifying oil red $\mathrm{O}$ staining (Figure 5, A and B, and Supplemental Figure 6) and leptin secretion (Figure 5C and Supplemental Figure 6). TG content was 3 -fold higher $(P<0.05$; Figure $5 \mathrm{~B})$, and leptin secretion was twice as high, in the DKO-differentiated MEFs as in WT MEFs after 10 days of differentiation $(P<0.01$; Figure 5C).
Next, we investigated the expression of PPAR $\gamma$, which is a key regulator of adipocyte differentiation (35). PPAR $\gamma$ is induced prior to the transcriptional activation of most adipocyte-specific genes, and its ectopic expression in nonadipogenic fibroblasts is sufficient to initiate adipocyte differentiation (35). Furthermore, PPAR $\gamma$ is required to promote fat cell differentiation, as PPAR $\gamma$-deficient cells fail to differentiate into adipocytes $(36,37)$. PPAR $\gamma$ mRNA was detected 2 days after onset of differentiation in WT MEFs following IBMX/DEX/IND treatment and was further elevated at days 4 and 6 (Figure 5D). Concomitant with the increased lipid accumulation and leptin secretion, 4E-BP1 and 4E-BP2 deletion resulted in higher expression of PPAR $\gamma$ mRNA in MEFs, reflecting the increased number of adipocyte-differentiated cells (Figure 5D). The expression of PPAR $\gamma$ and adipocyte differentiation is controlled by the members of the C/EBP family $(35,38,39)$. We therefore examined the expression of C/EBP family mRNAs following induction of adipocyte differentiation by IBMX/DEX/IND in MEFs. Expression of $\mathrm{C} / \mathrm{EBP} \alpha \mathrm{mRNA}$, which is required for adipocyte differentiation, was increased in DKO MEFs compared with WT MEFs (Figure 5D). Primary preadipocytes freshly isolated from gonadal adipose tissue were also induced to differentiate into mature adipocytes. Differentiation, as well as PPAR $\gamma$ and C/EBP $\alpha$ expression, were markedly increased in the DKO-isolated adipocytes (Figure 5, E and F). The 
onset and level of C/EBP $\beta$ mRNA expression was similar in DKO and WT MEFs (Figure 5D). In contrast, C/EBPS expression, which is required for the subsequent expression of C/EBP $\alpha$ and PPAR $\gamma$ in the later phases of differentiation (35), was increased in DKO MEFs during the early stages of differentiation (Figure 5D).

To confirm the role of 4E-BP1 and 4E-BP2 in the control of adipocyte differentiation, 4E-BP1 was transfected in 4E-BP1 KO MEFs and 4E-BP2 was transfected in 4E-BP2 KO MEFs prior to differentiation. Single deletion of 4E-BP1 or 4E-BP2 in MEFs led to increased adipocyte differentiation, as demonstrated by increased C/EBPS, $\mathrm{C} / \mathrm{EBP} \alpha$, and PPAR $\gamma$ mRNA expression (Supplemental Figure 6). Reintroduction of 4E-BP1 or 4E-BP2 in the respective KO MEFs caused reduced expression of the former transcription factors to a level similar to that seen in WT mice (Supplemental Figure 6). Taken together, these results implicate 4E-BPs in the control of $\mathrm{C} / \mathrm{EBP} \delta$ expression and suggest that increased expression of C/EBPS in the DKO cells may be responsible for the subsequent increased expression of PPAR $\gamma$ and $\mathrm{C} / \mathrm{EBP} \alpha$ and increased adipogenesis.

\section{Discussion}

Deregulation of the mTOR pathway leads to obesity and insulin resistance $(11,12,17,18,27)$. Here, we demonstrated that in the absence of the mTOR targets 4E-BP1 and 4E-BP2, mice developed a more severe HFD-induced obesity. Reduced energy expenditure, reduced lipolysis, and increased fatty acid reesterification contributed to this phenotype. We also showed increased adipogenesis in MEFs and preadipocytes isolated from DKO mice, as demonstrated by alterations in leptin secretion and TG accumulation as well as expression of 3 transcription factors specifically involved in adipogenesis, C/EBP, $\mathrm{C} / \mathrm{EBP} \alpha$, and PPAR $\gamma$.

Deletion of 4E-BP1 and 4E-BP2 in mice also led to activation of S6K1, which likely contributed to the insulin-resistant phenotype of the DKO mice. An attractive molecular model to explain this phenotype is based on the finding that S6K1 phosphorylates IRS-1 on Ser636/639 and Ser307, leading to inhibition of IRS-1 and downregulation of the PI3K/Akt pathway $(11,13)$. The role of S6K1 in the development of insulin resistance was directly demonstrated using S6K1 KO mice. Whereas HFD feeding normally causes impairment of insulin-induced Akt activation in muscle, liver, and adipose tissue, Akt insulin sensitivity is maintained in S6K1 KO mice (11). Regulatory associated protein of mTOR (raptor) serves as an adaptor protein that binds to mTOR and its substrates, S6K1 and 4E-BP1 $(40,41)$, through their TOR signaling motif (TOS) (42). It is therefore conceivable that S6K1 and $4 \mathrm{E}-\mathrm{BPs}$ compete for binding to raptor. Consequently, deletion of $4 \mathrm{E}-\mathrm{BP} 1$ and 4E-BP2 should increase the binding of S6K1 to raptor, which in turn should enhance $\mathrm{S} 6 \mathrm{~K}$ phosphorylation by $\mathrm{mTOR}$. Indeed, increased S6K activity was observed in DKO mice, as measured by insulin-stimulated $\mathrm{S} 6$ protein phosphorylation and reduced Akt phosphorylation in peripheral tissues. We failed to immunoprecipitate endogenous S6K and 4E-BP1 with raptor (O. Le Bacquer, unpublished observations). We note that the interaction between 4E-BPs or S6Ks with raptor was only reported with exogenously expressed proteins (40, 42, 43). However, consistent with our model and previous publications, the increase in S6K activity resulted in enhanced IRS-1 phosphorylation on amino acid residues Ser636/639 and Ser1101, 2 residues known to be involved in impairing insulin signaling $(11,23,28)$. In addition, deletion of 4E-BP1 and 4E-BP2 resulted in reduced expression of IRS-1. Because activation of S6K in TSC1/2 MEFs leads to a reduction in IRS-1 levels (18), we postulate that the increased S6K activity in our model is responsible for reduced IRS-1 expression in adipose tissue. These data indicate that 4E-BPs regulate insulin sensitivity and suggest that 4E-BPs indirectly control S6K activity through competition for binding to raptor and subsequent phosphorylation by mTOR.

Previous work using 4E-BP1 $\mathrm{KO}$ mice in mixed genetic backgrounds (129SvJ1 BALB/c, ref. 10, and 129Sv C57BL/6J, ref. 44) demonstrated a $10 \%$ reduction in body weight mainly due to reduced adipose tissue and increased energy expenditure (10). Here we used inbred $\mathrm{BALB} / \mathrm{c}$ mice to analyze the effect of genetic background on the 4E-BP1 KO phenotype. Surprisingly, whereas deletion of 4E-BP1 or 4E-BP2 in the C57BL/6J background results in a lean phenotype (ref. 44 and our unpublished observations), in $\mathrm{BALB} / \mathrm{c}$ mice, $\mathrm{KO}$ of $4 \mathrm{E}-\mathrm{BP} 1$ or $4 \mathrm{E}-\mathrm{BP} 2$ promotes increased body weight and fat accumulation compared with WT. These results suggest the existence of modifier genes that modulate the activity of 4E-BPs. Phenotypic differences in the development of the metabolic syndrome resulting from genetic background have been abundantly documented. One example is the highly penetrant $L e p^{o b}$ mutation of the gene encoding leptin $(45,46)$. The $o b$ mutation in the $\mathrm{BALB} / \mathrm{c}$ background results in a $60 \%$ reduction in white adipose tissue compared with $\mathrm{C} 57 \mathrm{BL} / 6 \mathrm{~J} o b / o b$ mice (45). Similarly, comparing C57BL/6J with FVB/N mice, Haluzik et al. demonstrated that genetic background strongly influences the severity of diabetes and insulin resistance in $o b / o b$ mice (46). Finally, congenic strains carrying the same null mutation can sometimes show widely divergent phenotypes, depending on the genotype of the recipient strain (47).

Recent studies using Drosophila describing its 4E-BP equivalent, $\mathrm{d} 4 \mathrm{E}-\mathrm{BP}$, as a metabolic brake under stress conditions $(48,49)$ concur with the DKO phenotype described herein. Deletion of melted leads to reduced fat accumulation in Drosophila (48). Interestingly, the melted deletion also results in reduced dTOR activity and increased d4E-BP expression in fat tissue (48) and produces a Drosophila with $40 \%$ less fat than WT. These data raise the possibility that $\mathrm{d} 4 \mathrm{E}-\mathrm{BP}$ regulates fat accumulation in Drosophila. Our observation that DKO mice had increased adiposity is consistent with this hypothesis.

Another possible mechanism that contributes to increased adiposity in DKO mice may be through increased adipocyte differentiation. Adipogenesis is the process by which immature preadipocytes differentiate into mature fat-accumulating adipocytes. This process is dependent on the orchestrated expression of transcription factors, including the C/EBP family and PPAR $\gamma$ (35). C/EBP $\beta$ and C/EBPS are expressed during the early phases of differentiation and are required for the subsequent expression of $\mathrm{C} / \mathrm{EBP} \alpha$ and PPAR $\gamma$ in the later phases (35). Although the transcriptional events controlling adipogenesis are well established, the upstream signaling pathway leading to activation of the adipogenic cascade is still not fully understood. Recently, several studies using rapamycin demonstrated a link between the mTOR pathway and adipogenesis $(14,16)$. Here, we provide direct evidence that 4E-BPs, known mTOR targets, are involved in the control of adipocyte differentiation. In a recent study, Kim et al. showed that rapamycin inhibits adipocyte differentiation through specific inhibition of $\mathrm{C} / \mathrm{EBP} \alpha$ and PPAR $\gamma$ expression (14). In DKO cells, we observed increased expression of an early marker of adipogenesis, C/EBP , which may be responsible for the subsequent increased expression of C/EBP $\alpha$ and PPAR $\gamma$, leading to increased adipogenesis. In preadipocytes, expression of $\mathrm{C} / \mathrm{EBP} \beta$ and $\mathrm{C} / \mathrm{EBP} \delta$ is upregulated by activation of 
the prostacyclin receptor, which induces binding of CREB (cAMP responsive element binding protein) and/or ATF-1 (activation transcription factor 1) to C/EBP promoters (50). In HepG2 cells, the induction of C/EBPS by IL-6 is mediated by STAT3 (51). STAT3 is also abundantly expressed in preadipocytes and adipocytes (52), and induction of adipocyte differentiation increases its expression (53). Interestingly, STAT3 is one of the transcriptional regulators that is phosphorylated and activated by mTOR (54). The fact that we did not see differences between WT and DKO cells in the expression of $\mathrm{C} / \mathrm{EBP} \beta$, only in that of C/EBPS, and that we observed increased mTOR activity as demonstrated by increased S6K1 phosphorylation, renders STAT3 an attractive candidate to explain the increased C/EBPS expression in DKO adipogenesis.

An important question raised by our findings is why ablation of 4E-BPs results in a metabolic phenotype, given the pleiotropic roles of these proteins. The development of a metabolic phenotype may result from impaired insulin action in peripheral tissues. Deletion of S6K1 protects against age- and diet-induced obesity while enhancing insulin sensitivity (11). In S6K1 KO mice fed a HFD, Akt signaling is not reduced, as it is in WT mice fed the same diet (11). Interestingly, S6K1 also regulates insulin levels. S6K1 KO mice exhibit a sharp reduction in glucose-induced insulin secretion and in pancreatic insulin content (9). This phenotype has been explained by a reduction in pancreatic endocrine mass, which is attributable to a selective decrease in $\beta$ cell size (9). In our mouse model, we observed increased S6K1 activity in liver, muscle, and adipose tissue leading to insulin desensitization through increased negative feedback of S6K1 on IRS-1. We also observed increased insulin levels even in mice fed the normal chow diet. It is also noteworthy that both 4E-BP1 and 4E-BP2 are expressed in the pancreas (10), which suggests that the increased S6K1 activity observed in our system might be responsible for the increased insulin levels.

In conclusion, we demonstrated that a deficiency of both 4E-BP1 and 4E-BP2 contributed to the development of obesity through increased adipogenesis and fat metabolism alterations. We also demonstrated that 4E-BPs played a role in the control of insulin sensitivity by modulating S6K activity. These data bolster the idea that an overactivated mTOR pathway plays an important role in the development of the metabolic syndrome. Thus, 4E-BPs may be potential drug targets in the treatment of patients suffering from obesity and/or insulin resistance.

\section{Methods}

Animals. All experiments were approved by the McGill University Animal Resource Center committee. Eiftebp 1 and Eif4ebp 2 mutant mice were generated as previously described $(10,55)$. Congenic BALB/c Eif4ebp $1^{-/-}$and Eiftebp $2^{--}$mice were obtained by backcrossing the original knockout strains independently for 10 generations to inbred BALB/c mice from Charles River Laboratories. BALB/c Eif4ebp1 and Eif4ebp2 heterozygous mice were then intercrossed to obtain BALB/c Eif4ebp1;Eif4ebp2 DKO mice (Supplemental Figure 1). Mice were housed in plastic cages and maintained at $22^{\circ} \mathrm{C}$ with a 12 -hour dark, 12 -hour light schedule. Eight-week-old animals were fed either a control normal chow diet (D12450B; 20\% protein, $70 \%$ carbohydrate, and $10 \%$ fat) or a HFD (D12492; $20 \%$ protein, $20 \%$ carbohydrate, and $60 \%$ fat) for 16 weeks (Research Diets Inc.).

Materials and chemicals. All cell culture solutions and supplements were purchased from Invitrogen. FBS was purchased from Sigma-Aldrich. Reagents for SDS-PAGE were purchased from Bio-Rad. The enhanced chemiluminescence kit was obtained from PerkinElmer. Anti-mouse and anti-rabbit IgGs conjugated to horseradish peroxidase were purchased from Amersham
Biosciences. Human insulin (Humalog) used for insulin resistance tests was obtained from Eli Lilly \& $\mathrm{Co}$. For the adipogenesis experiment, insulin, 3,3',5-triiodo-L-thyronine, DEX, IBMX, and IND were obtained from SigmaAldrich. D- $\left[1-{ }^{14} \mathrm{C}\right]$ glucose, $\left[{ }^{3} \mathrm{H}\right]$ oleic acid, and $\left[{ }^{3} \mathrm{H}\right]$ mevalonolactone were purchased from PerkinElmer, and Alumina oxide 06300 Fluka for chromatography and all other chemicals were from Sigma-Aldrich.

Metabolic studies. Eight-week-old male mice were fed ad libitum with either the normal chow diet or the HFD for 16 weeks. Body weight was recorded weekly, and food intake was measured every day for 15 consecutive days at the end of the diet. To test for insulin resistance, fed animals were intraperitoneally injected with $0.75 \mathrm{U} / \mathrm{kg}$ insulin, and the glucose concentration in whole blood from the tail vein was measured at 0,15 , 30, 45, and 60 minutes using an AccuSoft advantage glucometer (Roche Diagnostics). A glucose tolerance test was performed after overnight fasting. Mice were intraperitoneally injected with $2 \mathrm{~g} / \mathrm{kg}$ glucose, and blood glucose levels were measured at 0, 30, 60, 90, and 120 minutes. Fasting insulin and leptin levels were measured by ELISA (ALPCO Diagnostic and R\&D Systems). TG, cholesterol, and HDL-cholesterol levels were measured using detection kits (Roche Diagnostics). NEFAs were measured using a NEFA C kit (Wako).

$\mathrm{VO}_{2}$ measurement. $\mathrm{VO}_{2}$, carbon dioxide production, and the respiratory quotient were analyzed during a 48-hour time period. Continuous measurements were made during 24-hour time periods in an open circuit system with an oxygen analyzer (S-3A1; Applied Electrochemistry; AEI Technologies Inc.) and carbon dioxide analyzer (CD-3A; Applied Electrochemistry; AEI Technologies Inc.). $\mathrm{VO}_{2}$ was calculated as $\mathrm{ml} / \mathrm{kg} / \mathrm{h}$.

Histology and morphometric analysis of liver and adipose tissue. Paraffin-embedded adipose tissue and liver sections were analyzed by hematoxylin and eosin staining as previously described (10). Morphometric analysis of gonadal white adipose tissue from 500 cells from 3 different animals per genotype was performed with NIH ImageJ software (http://rsb.info.nih.gov/ij/).

RT-PCR analysis. Total RNA was extracted using TRIzOL (Invitrogen) according to the manufacturer's instructions. Total RNA (100 ng) was amplified using the Platinum qRT-PCR Thermoscript One-Step System (Invitrogen). The primers used in the PCR were as follows: C/EBP $\beta$, sense 5'-GCAAGAGCCGCGACAAG-3', antisense 5'-GGCTCGGGCAGCTGCTT-3'; C/EBP $\delta$, sense 5'-GCCTTTGAGACTCTGAACG-3, antisense 5'-TGTACCTTAGCTGCAATGG-3; C/EBP $\alpha$, sense 5'-GAACAGCAACGAGTACCGGGTA- ${ }^{\prime}$, antisense $5^{\prime}$-GCCATGGCCTTGACCAAGGAG-3'; PPAR $\gamma$, sense $5^{\prime}$-CCAGAGCATGGTGCCTTCGCT-3', antisense 5'-CAGCAACCATTGGGTCAGCTC-3'; $\beta$-actin, sense $5^{\prime}$-GGACTCCTATGTGGGTGACGAGG-3', antisense 5'-GGGAGAGCATAGCCCTCGTAGAT-3'.

Western blot analysis. Tissues were harvested in lysis buffer containing 40 mM HEPES ( $\mathrm{pH} 7.5$ ), $120 \mathrm{mM} \mathrm{NaCl}, 1 \mathrm{mM}$ EDTA, $10 \mathrm{mM}$ pyrophosphate, $10 \mathrm{mM}$ glycerophosphate, $50 \mathrm{mM} \mathrm{NaF}, 1.5 \mathrm{mM}$ sodium orthovanadate, $10 \mu \mathrm{M}$ okadaic acid, $10 \mu \mathrm{g} / \mathrm{ml}$ aprotinin, and $10 \mu \mathrm{g} / \mathrm{ml}$ leupeptin. After lysis, insoluble material was removed by centrifugation at $12,000 \mathrm{~g}$ for $10 \mathrm{~min}$ utes at $4{ }^{\circ} \mathrm{C}$. Protein content was determined by the Bradford protein assay (Bio-Rad). Equal amounts of protein were treated with Laemmli sample buffer. Proteins were separated by SDS-PAGE and transferred to nitrocellulose membranes. The membranes were blocked for 1 hour with $5 \%$ nonfat dry milk in PBS containing 0.1\% (v/v) Tween-20 and incubated overnight with primary antibody. Primary antibodies were detected with peroxidasecoupled secondary antibody and enhanced chemiluminescence (Amersham Biosciences). Antibodies against 4E-BP1, Akt, Ser473-phosphorylated Akt, S6K, Thr389-phosphorylated S6K, S6, Ser240/244-phosphorylated S6, Ser636/639-phosphorylated IRS-1, and Ser565-phosphorylated HSL were purchased from Cell Signaling Technology. IRS-1 antibody was purchased from Upstate USA Inc. Ser1101-phosphorylated IRS-1 antibody was a gift from R.D. Polakiewicz (Cell Signaling Technology, Danvers, Massachu- 
setts, USA). Anti-HSL and -perilipin antibodies were a gift from C. Londos (NIH, Bethesda, Maryland, USA).

Adipocyte differentiation of primary MEFs and isolated preadipocytes. Adipocytes and their precursor cells were isolated from WT and DKO gonadal white adipose tissue by collagenase digestion as previously described (34) and differentiated as described for MEFs. Primary MEFs (passage 0 or 1 ) from 13.5- to 14.5-day-old embryos were grown to confluence (day 0) in differentiation medium (DMEM containing 10\% FBS supplemented with

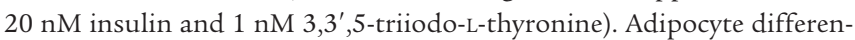
tiation was induced for 2 days by treating confluent cells for 48 hours in differentiation medium further supplemented with $500 \mu \mathrm{M}$ IBMX, 500 $\mathrm{nM}$ DEX, and $125 \mu \mathrm{M}$ IND. After this induction period, the medium was replaced with differentiation medium, which was then changed every second day. After 4 additional days in differentiation medium (day 6), the cells exhibited a fully differentiated phenotype with massive accumulation of multilocular fat droplets.

Oil red $O$ staining. Cells grown in tissue culture dishes were washed twice with PBS and fixed with $10 \%$ buffered formaldehyde for at least 1 hour at room temperature. The cells were then stained for 2 hours at room temperature with a filtered $0.5 \%$ oil red $\mathrm{O}$ solution (in isopropanol), extensively washed with distilled water, and visualized. TG content was determined after lipid extraction using Dye extract (Chemicon International).

Primary $M E F$ infection with $4 E-B P 1$ and $4 E-B P 2$ retrovirus. The human 4E-BP1 and 4E-BP2 cDNAs were subcloned into the MSCV-IRES-GFP retroviral plasmid (gift from J. Pelletier, McGill University, Montréal, Canada). Retroviruses were produced in Phoenix 293 cells by transfection using Lipofectamine Plus reagent (Invitrogen). Supernatants (48 hours after transfection) were used to infect early passage MEFs each day for 3 days in the presence of polybrene $(5 \mu \mathrm{g} / \mathrm{ml})$. The infection efficiency was monitored by the presence of GFP. Differentiation was then induced using confluent cultures.

Lipolysis and lipogenesis assays. Gonadal adipose tissue (after 2 weeks of diet) was collected and placed in MEM at room temperature. The tissue was rinsed with PBS, cut into small pieces, placed into a 48-well plate, and then treated with PBS, $100 \mathrm{nM}$ insulin, or $10 \mu \mathrm{M}$ isoproterenol and incubated for 3 hours at $37^{\circ} \mathrm{C}$ in $5 \mathrm{mM}$ glucose $\mathrm{Ca}^{2+}$-free Krebs-Ringer buffer (56) containing $1 \%$ fatty acid-free BSA and $1 \mu \mathrm{Ci} / \mu \mathrm{l}$ D- $\left[1-{ }^{14} \mathrm{C}\right]$ glucose. For the stimulation of lipolysis, we used isoproterenol, as opposed to epinephrine or catecholamine, as it is a pure $\beta$-agonist and as such elicits a greater lipolytic response. Following incubation, the plate was placed on ice, and the buffer was removed and stored at $-20^{\circ} \mathrm{C}$ for future NEFA and glycerol release analysis. Lipids were extracted from the tissue fragments overnight in heptane/isopropanol (3:2 ratio) at $-20^{\circ} \mathrm{C}$. The following day, lipids were reextracted from the tissue fragments with a second addition of heptaneisopropanol solution, and the 2 pools were combined and lyophilized. To select for neutral lipids (TGs), phospholipids were bound to Alumina by adding heptane/isopropanol (3:2 ratio) and Alumina to each sample. The samples were mixed for 15 minutes on a flat shaker at room temperature and centrifuged at $800 \mathrm{~g}$ for 15 minutes at $4^{\circ} \mathrm{C}$, and the supernatant was transferred to a scintillation vial and counted for 5 minutes. The amount of tissue-released NEFA and glycerol was measured using the commercial NEFA C kit from Wako and the TG kit from Roche Diagnostics. Soluble cell protein was dissolved in $0.1 \mathrm{~N} \mathrm{NaOH}$, the protein concentration was measured with the Bradford assay (Bio-Rad), and values were presented relative to total protein (in $\mu \mathrm{g}$ ).

Statistics. Analysis was performed by 2-tailed, unpaired Student's $t$ test or by 2 -way ANOVA as indicated in the figure and table legends. A $P$ value less than 0.05 was considered significant.

\section{Acknowledgments}

We thank C. Lister, P. Kirk, and K. Zwicker for excellent technical assistance and J. Penney and A. Sylvestre for maintaining the mouse colonies. We thank R.D. Polakiewicz for the Ser1101-phosphorylated IRS-1 antibody, C. Londos for anti-HSL and anti-perilipin antibodies, and Y.H. Tseng for helpful discussions on adipogenesis. This work was supported by a grant from the Canadian Institutes for Health Research (CIHR) to N. Sonenberg, who is a CIHR Distinguished Scientist and a Howard Hughes Medical Institute International Research Scholar. O. Le Bacquer and E. Petroulakis are recipients of McGill University Postdoctoral Fellowships, K. Cianflone is a Senior Canada Research Chair scholar and is funded by CIHR, and F. Poulin was supported by a Doctoral Award from CIHR.

Received for publication June 27, 2006, and accepted in revised form December 19, 2006.

Address correspondence to: Nahum Sonenberg, McGill University, Department of Biochemistry, McIntyre Medical Science Building, 3655 Promenade Sir William Osler, room 807, Montréal, Quebec H3G 1Y6, Canada. Phone: (514) 398-7274; Fax: (514) 398-1287; E-mail: nahum.sonenberg@mcgill.ca.

Francis Poulin's present address is: Department of Integrative Biology, University of California, Berkeley, Berkeley, California, USA.
1. Raught, B., Gingras, A.C., and Sonenberg, N. 2000. Regulation of ribosomal recruitment in eukaryotes. In Translational control of gene expression. N. Sonenberg, J.W.B. Hershey, and M.B. Matthews, editors. Cold Spring Harbor Laboratory Press. Cold Spring Harbor, New York, USA. 245-293.

2. Gingras, A.C., Raught, B., and Sonenberg, N. 1999. eIF4 initiation factors: effectors of mRNA recruitment to ribosomes and regulators of translation. Annu. Rev. Biochem. 68:913-963.

3. Hershey, J.W., and Merrick, W. 2000. Pathway and mechanism of initiation of protein synthesis. In Translational control of gene expression. N. Sonenberg, J.W. Hershey, and M.B. Matthews, editors. Cold Spring Harbor Laboratory Press. Cold Spring Harbor, New York, USA. 33-88.

4. Pause, A., et al. 1994. Insulin-dependent stimulation of protein synthesis by phosphorylation of a regulator of 5'-cap function. Nature. 371:762-767.

5. Poulin, F., Gingras, A.C., Olsen, H., Chevalier, S., and Sonenberg, N. 1998. 4E-BP3, a new member of the eukaryotic initiation factor 4E-binding protein family. J. Biol. Chem. 273:14002-14007.

6. Haghighat, A., Mader, S., Pause, A., and Sonenberg, N. 1995. Repression of cap-dependent translation by $4 \mathrm{E}-$ binding protein 1 : competition with $\mathrm{p} 220$ for binding to eukaryotic initiation factor-4E. EMBOJ. 14:5701-5709.

7. Raught, B., Gingras, A.C., and Sonenberg, N. 2001. The target of rapamycin (TOR) proteins. Proc. Natl. Acad. Sci. U. S. A. 98:7037-7044.

8. Hay, N., and Sonenberg, N. 2004. Upstream and downstream of mTOR. Genes Dev. 18:1926-1945.

9. Pende, M., et al. 2000. Hypoinsulinaemia, glucose intolerance and diminished beta-cell size in S6K1deficient mice. Nature. 408:994-997.

10. Tsukiyama-Kohara, K., et al. 2001. Adipose tissue reduction in mice lacking the translational inhibitor 4E-BP1. Nat. Med. 7:1128-1132.

11. Um, S.H., et al. 2004. Absence of S6K1 protects against age- and diet-induced obesity while enhancing insulin sensitivity. Nature. 431:200-205.

12. Khamzina, L., Veilleux, A., Bergeron, S., and Marette, A. 2005. Increased activation of the mam- malian target of rapamycin pathway in liver and skeletal muscle of obese rats: possible involvement in obesity-linked insulin resistance. Endocrinology. 146:1473-1481.

13. Tremblay, F., and Marette, A. 2001. Amino acid and insulin signaling via the $\mathrm{mTOR} / \mathrm{p} 70 \mathrm{~S} 6$ kinase pathway. A negative feedback mechanism leading to insulin resistance in skeletal muscle cells. J. Biol. Chem. 276:38052-38060.

14. Kim, J.E., and Chen, J. 2004. Regulation of peroxisome proliferator-activated receptor-gamma activity by mammalian target of rapamycin and amino acids in adipogenesis. Diabetes. 53:2748-2756.

15. Yeh, W.C., Bierer, B.E., and McKnight, S.L. 1995. Rapamycin inhibits clonal expansion and adipogenic differentiation of 3T3-L1 cells. Proc. Natl. Acad. Sci. U. S. A. 92:11086-11090.

16. Gagnon, A., Lau, S., and Sorisky, A. 2001. Rapamycin-sensitive phase of 3T3-L1 preadipocyte differentiation after clonal expansion. J. Cell. Physiol. 189:14-22.

17. Tzatsos, A., and Kandror, K.V. 2006. Nutrients sup- 
press phosphatidylinositol 3-kinase/Akt signaling via raptor-dependent mTOR-mediated insulin receptor substrate 1 phosphorylation. Mol. Cell. Biol. 26:63-76.

18. Harrington, L.S., et al. 2004. The TSC1-2 tumor suppressor controls insulin-PI3K signaling via regulation of IRS proteins. J. Cell Biol. 166:213-223.

19. Tee, A.R., Manning, B.D., Roux, P.P., Cantley, L.C., and Blenis, J. 2003. Tuberous sclerosis complex gene products, Tuberin and Hamartin, control mTOR signaling by acting as a GTPase-activating protein complex toward Rheb. Curr. Biol. 13:1259-1268.

20. Li, Y., Corradetti, M.N., Inoki, K., and Guan, K.L. 2004. TSC2: filling the GAP in the mTOR signaling pathway. Trends Biochem. Sci. 29:32-38.

21. Radimerski, T., Montagne, J., Hemmings-Mieszczak, M., and Thomas, G. 2002. Lethality of Drosophila lacking TSC tumor suppressor function rescued by reducing dS6K signaling. Genes Dev. 16:2627-2632.

22. Zhang, H., et al. 2003. Loss of Tsc1/Tsc2 activates mTOR and disrupts PI3K-Akt signaling through downregulation of PDGFR. J. Clin. Invest. 112:1223-1233. doi:10.1172/JCI200317222.

23. Bouzakri, K., et al. 2003. Reduced activation of phosphatidylinositol-3 kinase and increased serine 636 phosphorylation of insulin receptor substrate- 1 in primary culture of skeletal muscle cells from patients with type 2 diabetes. Diabetes. 52:1319-1325.

24. Faraj, M., Lu, H.L., and Cianflone, K. 2004. Diabetes, lipids, and adipocyte secretagogues. Biochem. Cell Biol. 82:170-190.

25. Unger, R.H. 2003. Lipid overload and overflow: metabolic trauma and the metabolic syndrome. Trends Endocrinol. Metab. 14:398-403.

26. Lebovitz, H.E., and Banerji, M.A. 2005. Point: visceral adiposity is causally related to insulin resistance. Diabetes Care. 28:2322-2325.

27. Shah, O.J., Wang, Z., and Hunter, T. 2004. Inappropriate activation of the TSC/Rheb/mTOR/ S6K cassette induces IRS1/2 depletion, insulin resistance, and cell survival deficiencies. Curr. Biol. 14:1650-1656.

28. Li, Y., et al. 2004. Protein kinase C Theta inhibits insulin signaling by phosphorylating IRS1 at Ser(1101). J. Biol. Chem. 279:45304-45307.

29. Daval, M., et al. 2005. Anti-lipolytic action of AMPactivated protein kinase in rodent adipocytes. J. Biol. Chem. 280:25250-25257.

30. Garton, A.J., et al. 1989. Phosphorylation of bovine hormone-sensitive lipase by the AMP-activated protein kinase. A possible antilipolytic mechanism. Eur. J. Biochem. 179:249-254.
31. Zechner, R., Strauss, J.G., Haemmerle, G., Lass, A., and Zimmermann, R. 2005. Lipolysis: pathway under construction. Curr. Opin. Lipidol. 16:333-340.

32. Souza, S.C., et al. 1998. Overexpression of perilipin $A$ and B blocks the ability of tumor necrosis factor alpha to increase lipolysis in 3T3-L1 adipocytes. J. Biol. Chem. 273:24665-24669.

33. Forest, C., et al. 2003. Fatty acid recycling in adipocytes: a role for glyceroneogenesis and phosphoenolpyruvate carboxykinase. Biochem. Soc. Trans. 31:1125-1129.

34. Tseng, Y.H., Kriauciunas, K.M., Kokkotou, E., and Kahn, C.R. 2004. Differential roles of insulin receptor substrates in brown adipocyte differentiation. Mol. Cell. Biol. 24:1918-1929.

35. Rosen, E.D., Walkey, C.J., Puigserver, P., and Spiegelman, B.M. 2000. Transcriptional regulation of adipogenesis. Genes Dev. 14:1293-1307.

36. Rosen, E.D., et al. 1999. PPAR gamma is required for the differentiation of adipose tissue in vivo and in vitro. Mol. Cell. 4:611-617.

37. Kubota, N., et al. 1999. PPAR gamma mediates high-fat diet-induced adipocyte hypertrophy and insulin resistance. Mol. Cell. 4:597-609.

38. Wu, Z., Bucher, N.L., and Farmer, S.R. 1996 Induction of peroxisome proliferator-activated receptor gamma during the conversion of $3 \mathrm{~T} 3$ fibroblasts into adipocytes is mediated by C/EBPbeta, C/EBPdelta, and glucocorticoids. Mol. Cell. Biol. 16:4128-4136.

39. Tanaka, T., Yoshida, N., Kishimoto, T., and Akira, S. 1997. Defective adipocyte differentiation in mice lacking the C/EBPbeta and/or C/EBPdelta gene. EMBO J. 16:7432-7443.

40. Hara, K., et al. 2002. Raptor, a binding partner of target of rapamycin (TOR), mediates TOR action. Cell. 110:177-189.

41. Kim, D.H., et al. 2002. mTOR interacts with raptor to form a nutrient-sensitive complex that signals to the cell growth machinery. Cell. 110:163-175.

42. Nojima, H., et al. 2003. The mammalian target of rapamycin (mTOR) partner, raptor, binds the mTOR substrates p70 S6 kinase and 4E-BP1 through their TOR signaling (TOS) motif. J. Biol. Chem. 278:15461-15464.

43. Schalm, S.S., Fingar, D.C., Sabatini, D.M., and Blenis, J. 2003. TOS motif-mediated raptor binding regulates 4E-BP1 multisite phosphorylation and function. Curr. Biol. 13:797-806.

44. Blackshear, P.J., Stumpo, D.J., Carballo, E., and Lawrence, J.C., Jr. 1997. Disruption of the gene encoding the mitogen-regulated translational modulator PHAS-I in mice. J. Biol. Chem. 272:31510-31514.
45. Qiu, J., Ogus, S., Mounzih, K., Ewart-Toland, A., and Chehab, F.F. 2001. Leptin-deficient mice backcrossed to the BALB/cJ genetic background have reduced adiposity, enhanced fertility, normal body temperature, and severe diabetes. Endocrinology. 142:3421-3425

46. Haluzik, M., et al. 2004. Genetic background $(\mathrm{C} 57 \mathrm{BL} / 6 \mathrm{~J}$ versus $\mathrm{FVB} / \mathrm{N})$ strongly influences the severity of diabetes and insulin resistance in $\mathrm{ob} / \mathrm{ob}$ mice. Endocrinology. 145:3258-3264.

47. Wolfer, D.P., Crusio, W.E., and Lipp, H.P. 2002. Knockout mice: simple solutions to the problems of genetic background and flanking genes. Trends Neurosci. 25:336-340.

48. Teleman, A.A., Chen, Y.W., and Cohen, S.M. 2005. Drosophila melted modulates FOXO and TOR activity. Dev. Cell. 9:271-281.

49. Teleman, A.A., Chen, Y.W., and Cohen, S.M. 2005 $4 \mathrm{E}-\mathrm{BP}$ functions as a metabolic brake used under stress conditions but not during normal growth. Genes Dev. 19:1844-1848.

50. Belmonte, N., et al. 2001. Activation of extracellular signal-regulated kinases and CREB/ATF-1 mediate the expression of CCAAT/enhancer binding proteins beta and -delta in preadipocytes. Mol. Endocrinol. 15:2037-2049.

51. Yamada, T., Tsuchiya, T., Osada, S., Nishihara, T., and Imagawa, M. 1998. CCAAT/enhancer-binding protein delta gene expression is mediated by autoregulation through downstream binding sites. Biochem. Biophys. Res. Commun. 242:88-92.

52. Deng, J., Hua, K., Lesser, S.S., and Harp, J.B. 2000. Activation of signal transducer and activator of transcription-3 during proliferative phases of 3T3L1 adipogenesis. Endocrinology. 141:2370-2376.

53. Harp, J.B., Franklin, D., Vanderpuije, A.A., and Gimble, J.M. 2001. Differential expression of signal transducers and activators of transcription during human adipogenesis. Biochem. Biophys. Res. Commun. 281:907-912.

54. Yokogami, K., Wakisaka, S., Avruch, J., and Reeves, S.A. 2000. Serine phosphorylation and maximal activation of STAT3 during CNTF signaling is mediated by the rapamycin target mTOR. Curr. Biol. 10:47-50.

55. Banko, J.L., et al. 2005. The translation repressor 4E-BP2 is critical for eIF4F complex formation, synaptic plasticity, and memory in the hippocampus. J. Neurosci. 25:9581-9590.

56. Faraj, M., and Cianflone, K. 2004. Differential regulation of fatty acid trapping in mouse adipose tissue and muscle by ASP. Am. J. Physiol. Endocrinol. Metab. 287:E150-E159. 